\title{
Properties of dune sand concrete containing coffee waste
}

\author{
Guendouz Mohamed $^{1}$, Boukhelkhal Djamila ${ }^{1}$ \\ ${ }^{1}$ LME Laboratory, University of Medea, Algeria
}

\begin{abstract}
In the last years, an increase of coffee beverages consumption has been observed all over the world; and its consumption increases the waste coffee grounds which will become an environmental problems. Recycling of this waste to produce new materials like sand concrete appears as one of the best solutions for reduces the problem of pollution. This work aims to study the possibility of recycling waste coffee grounds (Spent Coffee Grounds (SCG)) as a fine aggregate by replacing the sand in the manufacturing of dune sand concrete. For this; sand concrete mixes were prepared with substitution of sand with the spent coffee grounds waste at different percentage $(0 \%, 5 \%, 10 \%, 15 \%$ and $20 \%$ by volume of the sand) in order to study the influence of this wastes on physical (Workability, bulk density and porosity), mechanical (compressive and flexural strength) and Thermal (Thermal conductivity and thermal diffusivity) properties of dune sand concrete. The results showed that the use of spent coffee grounds waste as partial replacement of natural sand contributes to reduce workability, bulk density and mechanical strength of sand concrete mixes with an increase on its porosity. However, the thermal characteristics are improved and especially for a level of $15 \%$ and $20 \%$ of substitution. So, it is possible to obtain an insulating material which can be used in the various types of structural components. This study ensures that reusing of waste coffee grounds in dune sand concrete gives a positive approach to reduce the cost of materials and solve some environmental problems.
\end{abstract}

\section{Introduction}

The fraction of organic waste in household wastes is large and increases with time. In each country the waste composition is different, since it is affected by socioeconomic characteristics, consumption patterns and waste management programs, but generally the level of organic in waste components is high. Among these wastes is a coffee waste. The valorization of this type of waste can contribute to the reduction of pollution, and to manufacture new building materials [1-3].

Several works has already been done on the use of coffee waste as an aggregate in the preparation of cement mortar [4], concrete [5, 6] and Eco-fired clay bricks [7]. The authors in this works explored the use of light aggregate based on coffee waste, as a composite material reducing the workability, density, the cost, the brittleness, the thermal insulation properties and fire of building materials such as concrete, mortars or bricks. The results found by various authors showed that the properties of concrete containing spent coffee grounds aggregates as lightweight aggregate are similar or even better than those of concrete containing some other commonly used natural lightweight aggregates $[5,6]$. The lack of adhesion between the grain of spent coffee grounds and cement paste and the inhibition of cement hydration due to the cellular nature of SCG are the reasons indicated in several studies for the poor mechanical properties of concrete containing SCG [4].

This work focuses on the possibility of recycling waste coffee grounds without any prior treatment (SCG) as a partial replacement of natural aggregate in dune sand, in order to minimize the cost of the final material. The influence of the proportion of waste used (SCG) on properties of the new material has been studied and analyzed.

\section{Experimental}

\subsection{Materials}

The sand used in this work is a dune sand (DS) extracted from south of Algeria, with a maximum grain diameter of approximately $2 \mathrm{~mm}$; and the proportion of grains smaller than $0.08 \mathrm{~mm}$ is below $5 \%$. The particle size distributions of this sand are shown in Figure 1 and its physical characteristics are presented in Table 1.The $\mathrm{X}$-ray Diffraction analysis of dune sands demonstrates their siliceous nature "Figure 2" and the SEM investigation reveals the rounded shape of its grains "Figure 3". 


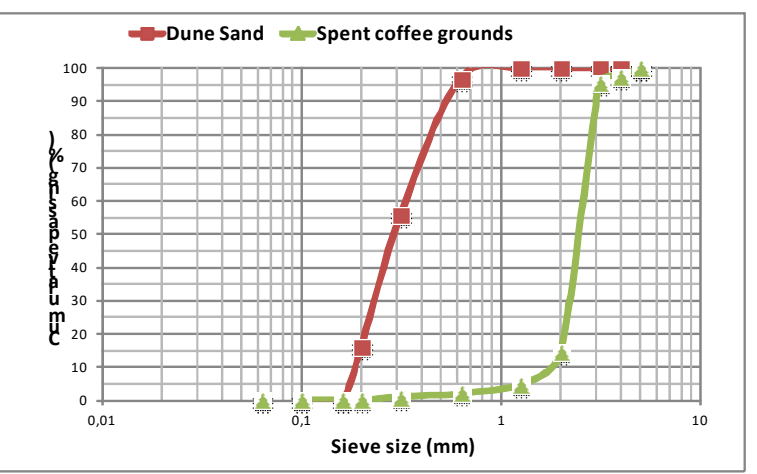

Fig. 1. Particle size distribution of sand and coffee waste used.

Table 1. Physical properties of used sand.

\begin{tabular}{|c|c|c|}
\hline Properties & Sand & Standard \\
\hline Bulk density $\left(\mathrm{kg} / \mathrm{m}^{3}\right)$ & 1400 & NP EN 1097-3 \\
\hline Specific density $\left(\mathrm{kg} / \mathrm{m}^{3}\right)$ & 2580 & NP EN 1097-6 \\
\hline Water absorption (\%) & 2.30 & NP EN 1097-6 \\
\hline Sand equivalent (\%) & 75.50 & NP EN 933-8 \\
\hline Fineness modulus & 1.16 & NP EN 933-1 \\
\hline Compactness (\%) & 0.54 & NF P 18-555 \\
\hline Porosity (\%) & 0.46 & NF P 18-555 \\
\hline $\begin{array}{c}\text { Thermal conductivity } \\
(\mathrm{W} / \mathrm{m} \mathrm{K})\end{array}$ & $1.3-1.4$ & $\begin{array}{c}\text { NF EN ISO } \\
8894-1\end{array}$ \\
\hline
\end{tabular}

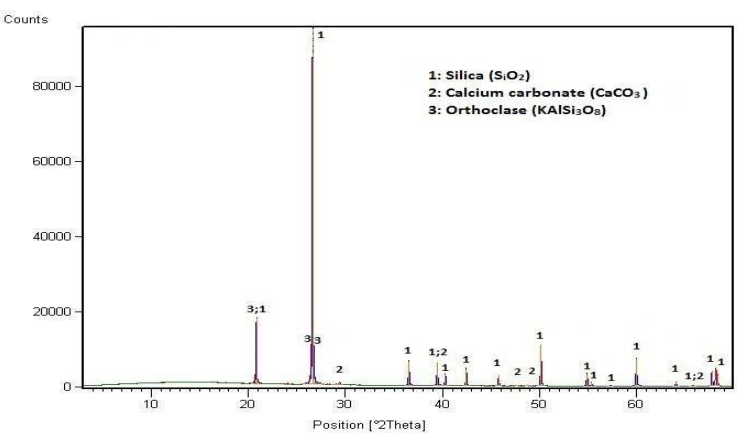

Fig. 2. X-ray diffractogram analysis of dune sand used.

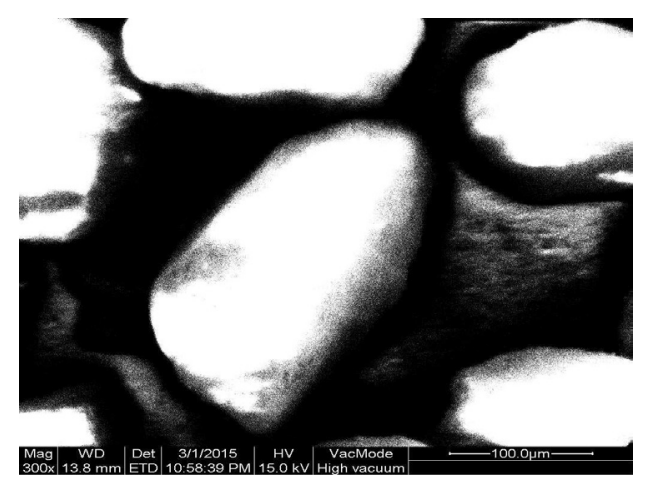

Portland cement CEM II/A 42.5 from MASCARA Factory in Algeria with a density of $3100 \mathrm{~kg} / \mathrm{m}^{3}$ was used throughout this study. The chemical analysis of this cement is presented in Table 2 .

Table 2. The chemical composition of cement used.

\begin{tabular}{|c|c|}
\hline Materials Oxides [\%) & Cement \\
\hline $\mathrm{SiO}_{2}$ & 23.83 \\
\hline $\mathrm{Al}_{2} \mathrm{O}_{3}$ & 6.05 \\
\hline $\mathrm{Fe}_{2} \mathrm{O}_{3}$ & 4.66 \\
\hline $\mathrm{CaO}$ & 56.35 \\
\hline $\mathrm{MgO}$ & 2.44 \\
\hline $\mathrm{K}_{2} \mathrm{O}$ & 0.83 \\
\hline $\mathrm{Na}_{2} \mathrm{O}$ & 0.58 \\
\hline $\mathrm{SO}_{3}$ & 2.37 \\
\hline $\mathrm{CaO}_{\text {Free }}$ & 0.76 \\
\hline $\mathrm{P} . \mathrm{F}$ & 2.23 \\
\hline Total & 99.86 \\
\hline
\end{tabular}

The use of fillers in sand concrete composition is essential [8]. Their use is intended to complete the grading curve of sand in its finest part in order to obtain more compact concrete, reduce the cement content and therefore the cost of concrete [9]. In this work the fillers used are the limestone powder. Their specific density is $2.857 \mathrm{~kg} / \mathrm{m}^{3}$, and specific surface area $310 \mathrm{~m}^{2} / \mathrm{kg}$.

The Spent coffee grounds (SCG) used in this work were obtained by recycling a local coffee shop (Arabica type), dried, and powdered after received and oven-dried at a temperature of $105^{\circ} \mathrm{C} \pm 2$. Figure 4 shows the SCG used in this work. It's a $4 \mathrm{~mm}$ maximum size "Figure 1". The chemical analysis of this SCG is presented in Table 3 and their physical and thermal properties are presented in Table 4.

Table 3. Chemical analysis of coffee wastes used.

\begin{tabular}{|c|c|}
\hline Elements & Quantity (\%) \\
\hline Carbone $(\mathrm{C})$ & 49.70 \\
\hline Hydrogen $(\mathrm{H})$ & s.d \\
\hline Azotes $(\mathrm{A})$ & 2.3 \\
\hline
\end{tabular}

Table 4. Physical and thermal properties of coffee wastes used.

\begin{tabular}{|c|c|}
\hline Properties & Spent coffee grounds \\
\hline Fineness modulus & 2.9 \\
\hline Bulk density $\left(\mathrm{kg} / \mathrm{m}^{3}\right)$ & 0.387 \\
\hline Specific density $\left(\mathrm{kg} / \mathrm{m}^{3}\right)$ & 0.8 \\
\hline Compactness $(\%)$ & 48.38 \\
\hline Porosity $(\%)$ & 51.62 \\
\hline Water absorption $(\%)$ & 0.9 \\
\hline Thermal conductivity $(\mathrm{W} / \mathrm{m} \mathrm{K})$ & 0.30 \\
\hline
\end{tabular}

Fig. 3. Scanning electron micrographs of used sand. 


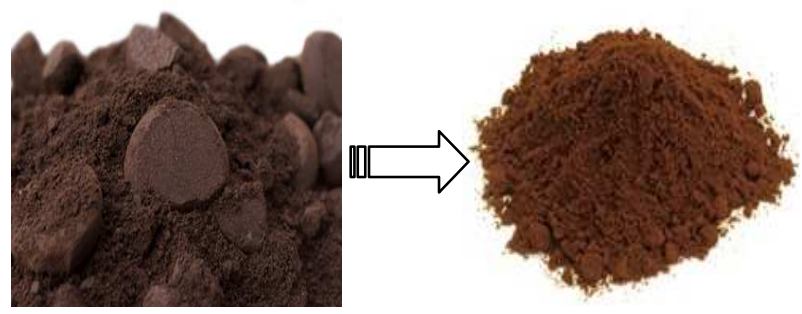

Fig.4. General aspect of used coffee waste.

In this work a polycarboxylate based plasticiser 'MEDAFLUID 104', with a liquid form; a chestnut color; a PH equal to 6 , a density of $1.04 \pm 0,01$ and a content of chlore $<1 \mathrm{~g} / \mathrm{L}$.

The mixing water used for the different mixes is the distribution drinking water.

\subsection{Mix design}

In this work, the optimal compositions of the dune sand concrete studied, without SCG, is based on the experimental method proposed from Sablocrete project [9]. The sand is substituted by volume with the SCG at dosages of $0,5,10,15$ and $20 \%$. Two types of SC mixtures were made. The mix proportions of each sand concrete are shown in Table 5.

The different manufactured sans concrete mixes will be noted as follows:

- CSC: Control sand concrete (Without spent coffee grounds).

- CSCG: Sand concrete with spent coffee grounds.

Table 5. Sand Concrete mixture proportion $\left(1 \mathrm{~m}^{3}\right)$.

\begin{tabular}{|c|c|c|c|c|c|}
\hline & \multirow{2}{*}{ CSC } & \multicolumn{4}{|c|}{ CSCG } \\
\cline { 3 - 6 } & & $5 \%$ & $10 \%$ & $15 \%$ & $20 \%$ \\
\hline Sand $\left(\mathrm{Kg} / \mathrm{m}^{3}\right)$ & 1320 & 1254 & 1188 & 1122 & 1056 \\
\hline Cement $\left(\mathrm{Kg} / \mathrm{m}^{3}\right)$ & 350 & 350 & 350 & 350 & 350 \\
\hline Fillers $\left.\mathrm{Kg} / \mathrm{m}^{3}\right)$ & 200 & 200 & 200 & 200 & 200 \\
\hline Water $\left(1 / \mathrm{m}^{3}\right)$ & 302.5 & 302.5 & 302.5 & 302.5 & 302.5 \\
\hline SCG $\left(\mathrm{Kg} / \mathrm{m}^{3}\right)$ & 00 & 19.34 & 38.64 & 58 & 77.36 \\
\hline $\mathrm{Pl}^{*}(\%)$ & 1 & 1.30 & 1.35 & 1.86 & 2 \\
\hline
\end{tabular}

*plasticizer

All specimens were produced in laboratory environment with $20^{\circ} \mathrm{C}$ and $50 \% \mathrm{RH}$. After $24 \mathrm{~h}$, they were removed from the molds and placed in water at $20^{\circ} \mathrm{C}$ and $100 \%$ relative humidity until the day of testing. This procedure was respected for all compositions and all tests.

\subsection{Tests Procedures}

The fresh dune sand concrete was characterized by it corresponding slump, determined with means of the Abrams cone test (NF P 18-451), and fresh density (EN 12350-6). For hardened sand concrete mixes, flexural strength was determined by using three points test for each composition on three $4 \times 4 \times 16 \mathrm{~cm}$ prismatic samples.
The half-samples resulting from this test were then submitted to compression test on a $4 \times 4 \mathrm{~cm}$ test section (EN 196-1). Sample size is significant in comparison with the size of aggregates.

In this study the porosity of dune sand concrete is measured on the base of total immersion test in water; with sample preparation under vacuum.

The thermal properties (conductivity and diffusivity) were measured using the CT-meter device (Fig. 5) on three $40 \times 80 \times 160 \mathrm{~mm}$ samples according to NF EN ISO 8894-1.

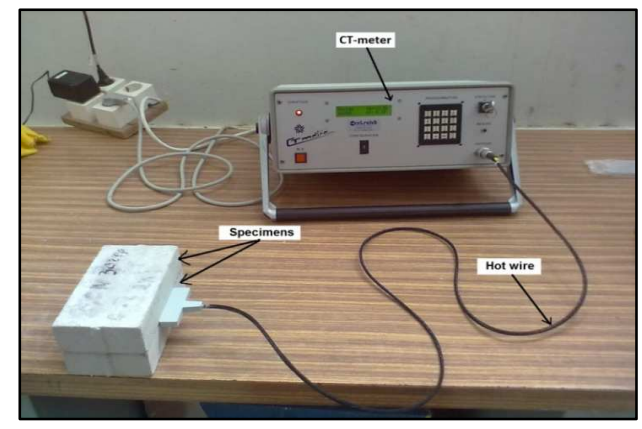

Fig. 5. Measurement of thermal properties.

\section{Results and discussion}

\subsection{Workability}

Figure 6 give the results of slump of dune sand concrete mixes as a function of SCG percentages. These results displayed that the use of SCG waste as replacement of sand contributes to decrease the slump about $77 \%$ of dune sand concrete. This reduction in value of slump probably due to the absorption of SCG grains compared to natural sand. The same result was obtained by other authors [5], who reported that the use of spent coffee grounds in concrete, involves a significant reduction in the workability.

In order to limit the number of compositions and to be able to compare them in hardened state on a common basis, it has been decided to carry out the research project at a constant workability (slump between $70 \mathrm{~mm}$ and 90 $\mathrm{mm}$ ) and adjusting the workability measure by adding the a quantity of plasticizer for each mixture contains coffee waste.

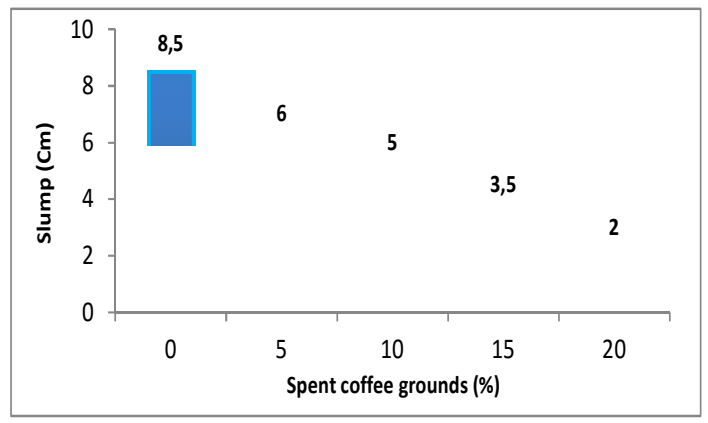

Fig.6. Slump of dune sand concrete as function of spent coffee grounds waste content. 


\subsection{Bulk density}

In figure 7, are presented the results of bulk density for sand concrete mixes as a function of SCG content. The results showed that the use of spent coffee grounds as partial replacement of naturel sand contributes to reduce the bulk density of dune sand concrete for about of $13 \%$. This is probably due to the lower density of the SCG compared with the natural sand. The values of fresh density decrease from $2008 \mathrm{~kg} / \mathrm{m}^{3}$ for mixtures without SCG waste to $1750 \mathrm{~kg} / \mathrm{m}^{3}$ for mixtures containing $20 \%$ of SCG for sand concrete. These results agree with those found by other researchers concrete $[4,5,10,11]$.

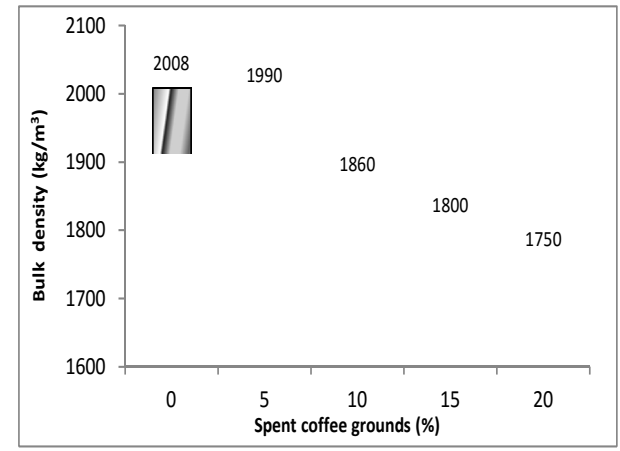

Fig.7. Bulk density of dune sand concrete as function of spent coffee grounds waste content.

\subsection{Porosity}

Inspecting the results in figure 8 , it is possible to observe a difference in terms of porosity between reference sand concrete and all the spent coffee grounds based sand concretes. While an increase on porosity of sand concrete is showed with the spent coffee grounds aggregates content increases. This increase of porosity may be related to a poor adhesion between the spent coffee grounds aggregate surface and binder paste. This result agrees with those observed by authors in $[12,13]$.

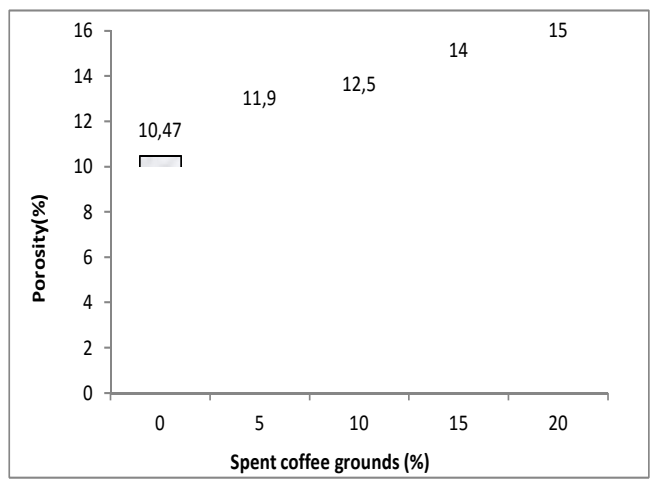

Fig.8. Porosity of dune sand concrete as function of spent coffee grounds waste content.

\subsection{Mechanical strength}

The compressive and flexural strength of different composites at 28 days of age are presented in Figure 9 and 10 respectively. The results show a decrease in compressive and flexural strength when the spent coffee grounds aggregates content increases (about $44 \%$ and $68 \%$ respectively with $20 \%$ of SCG content). This trend may be related to the porosity of different dune sand concrete containing SCG, which is likely, contributes to such a strong decay of mechanical properties. The same results are shown by Lin et al. [4] in a study on the use of coffee residue in mortar mixture as fine aggregate replacement. For the study of Velasco et al [7] on the use of spent coffee grounds in Eco-fired clay bricks, the authors observed a reduction of $65 \%$ in the compression strength which ranges from 38 to $14 \mathrm{~N} / \mathrm{mm}^{2}$ when $17 \%$ of spent coffee grounds are added.

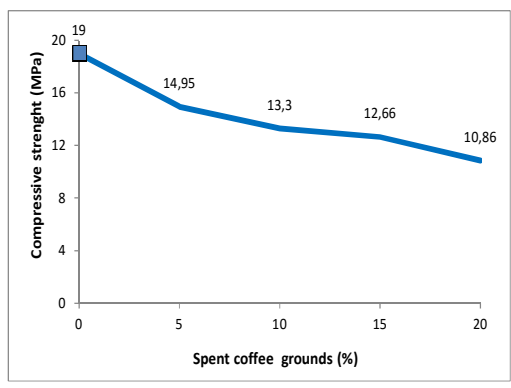

Fig.9. Compressive strength of dune sand concrete as function of spent coffee grounds waste content.

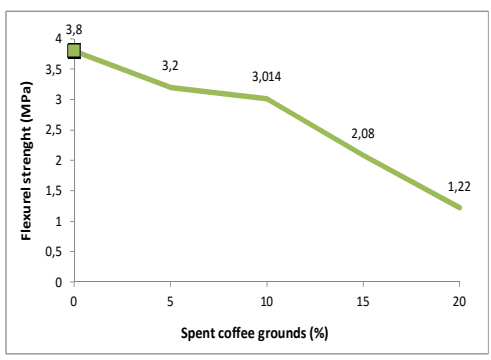

Fig.10.Flexurel strength of dune sand concrete as function of spent coffee grounds waste content.

\subsection{Thermal properties}

The thermal conductivity values of the specimens measured at 28 days are showed in Figure 11. While the Figure 12 shows the values of thermal diffusivity of different SC. The results show that the thermal properties of dune sand concrete decrease when the percentage of 
spent coffee grounds increase. Which is certainly due to the lower thermal conductivity coefficient of the SCG aggregate $(0.3 \mathrm{~W} / \mathrm{m} \mathrm{K})$ than natural dune sand $(1.4 \mathrm{~W} / \mathrm{m}$ K) [14]. On the other hand, the decreasing in thermal properties came also from the increase in porosity induced by the SCG. In fact the pores contain air which has a thermal conductivity $(0.024 \mathrm{~W} / \mathrm{mK})$ much lower than all the other components of the sand concrete [12]. Similar results were observed by several authors in composite systems, Velasco et al. [7] in a study on SCG in Eco-fired clay bricks, and it's showed a decreased in value of thermal conductivity from $0.74 \mathrm{~W} / \mathrm{m} \mathrm{K}$ for clay without additive to $0.36 \mathrm{~W} / \mathrm{m} \mathrm{K}$ when $17 \%$ of spent coffee grounds are added.

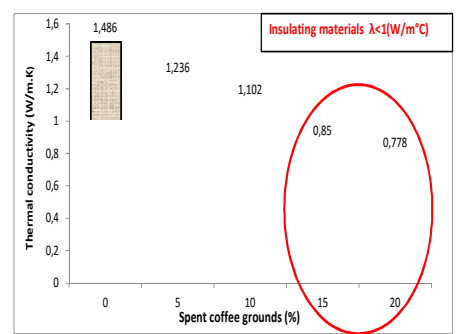

Fig.11.Thermal conductivity of dune sand concrete as function of spent coffee grounds waste content.

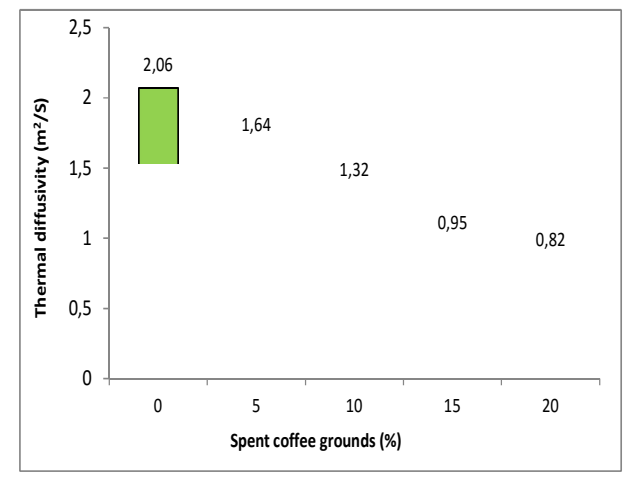

Fig.12. Thermal diffusivity of dune sand concrete as function of spent coffee grounds waste content.

\section{Conclusions}

This experimental work focuses on the effect of recycling coffee wastes on physical, mechanical and thermal properties of dune sand concrete. The ecological benefit of effectively utilizing this waste material is another prime motivation for this work. From the obtained results of this study, the following conclusions can be drawn:
1-The use of spent coffee grounds (SCG) as partial replacement of sand contributes to decrease the density of dune sand concrete as well as its workability of about $77 \%$.

2-The porosity of dune sand concrete increase with incorporation of coffee wastes.

3-The mechanical properties at age of 28 days of dune sand concrete decrease when the percentage of coffee waste increases. A decrease of $44 \%$ and $68 \%$ in compressive and flexural strength respectively when $20 \%$ of SCG-aggregates are added. But this result was acceptable for lightweight concrete.

4-Spent coffee grounds replacement with natural sand in mixture caused a reduction in the values of thermal conductivity of the sand concrete $(48 \%)$. The sand concretes containing $15 \%$ and $20 \%$ of SCG are regarded as insulating materials $\left(\lambda<1 \mathrm{~W} / \mathrm{m}^{\circ} \mathrm{C}\right)$.

Finally, this work insures that the recycling of coffee wastes in dune sand concrete gives a positive approach to conserve the environment and non-renewable natural material resources.

\section{References}

1. T. Tokimoto T, N. Kawasaki, T. Nakamura T, J. Akutagawa, S. Tanada. J. Colloid Interf. Sci. 281 ,56-61 (2005)

2. S. Mussatto, I. Carneiro, L. M. Silva , I.C. Roberto, J. Teixeira. Carbohydrate Polymers.83 ,368-374 (2011)

3. R. Cruz , P. Baptista ,S. Cunha ,J.A. Pereira , Casal. Carotenoids of lettuce. 17 (2012)

4. Lee- Kuo Lin .,Tsung-Min Kuo ., Yi-Shu Hsu. J.Mater Cycles Waste Manag.(2015)

5. LK . Lin.,SI. Yu . J Taiwan Env Eng Assoc. 21, 114 (2010)

6. YS. Hsu. Master Thesis. Institute of Civil and Disaster Prevention. Taipei. (2010)

7. P. Muñoz Velasco M., A. Mend1`vil M., P. Morales L., Muñoz.,.J Mater Stru. 49,641-650(2016)

8. AFNOR. Concrete - Sand concrete. Projet P 18-500 (1994).

9. Presse de l'Ecole Nationale des Ponts et Chaussées. 'Béton de sable: Caractéristiques et pratique d'utilisation'. (Projet SABLOCRETE) édition. (1994)

10. M. Guendouz ,F. Debieb ,O. Boukendakdji,E.H. Kadri, M. Bentchikou and H. Soualhi.J Mater and Env Scien, J. Mater. Environ. Sci. 4 (2013) $227-$ 232.7 (2).(2016),p.382-389.

11. M. Guendouz., F. Debieb and E.H. Kadri. 33èmes Rencontres de l'AUGC, ISABTP/UPPA, Anglet, 27 au 29 mai 2015 Bayonne, France, (2015 ),p 1-8.

12 F. Iucolano,B. Liguori, D. Caputo, F. Colangelo, R. Cioffi. J.Mater Desi.52,916-922 (2013)

13. S. Akcaozog $\$ lu, Ku. Akcaozog lu, C. Duran Atis. Thermal conductivity WPLA. Cons and Buil Mater, 66,247-258 (2013)

14. K. Hannawi,W. Prince,S. Kamali-Bernard., J.Waste Biomass Valorization 1,251-9(2010) . 